\title{
Age-related changes in factors associated with delayed extubation after general anesthesia: a retrospective study
}

\author{
Naoya Kobayashi', Toshihiro Wagatsuma, Takuya Shiga, Hiroaki Toyama, Yutaka Ejima and Masanori Yamauchi
}

\section{To the Editor}

The number of older adults who undergo surgical procedures has increased in recent years, especially in developed countries $[1,2]$. Early recovery is a primary goal when providing general anesthesia to older adults. Since previous studies revealed that shorter extubation times allow for early recovery and are associated with reduced pharmacological and perioperative complications [3-7], the extubation time (defined as the time elapsed from cessation of sedative drugs to extubation) has become a topic of interest to surgeons and anesthesia care providers. Although delayed extubation occurs more frequently in older than younger patients, age-related changes in factors influencing extubation times remain relatively unexplored. Therefore, we conducted a largescale retrospective analysis of the association between extubation times and covariates such as comorbidities, sedative and analgesic agents, operation methods, and intraoperative management in both older and younger patients.

We analyzed data from 9514 patients who underwent surgical procedures under general anesthesia in a university hospital between 2011 and 2015. Ethical approval was obtained from the Ethics Committee of Tohoku University Graduate School of Medicine (reference number: 2015-1-533). The requirement for informed consent was waived due to the retrospective nature of the study. Patients were divided into two groups according to age: one group comprised of patients aged less than 65 years ( $<65$ years) and the other group comprised of patients aged 65 years or more ( $\geq 65$ years). The extubation adopted the following commonly adopted criteria [8]: (1) consciousness: open eyes, fate response; (2) respiration: spontaneous breathing, appropriate respiratory rate $(<25 / \mathrm{min},>8 / \mathrm{min})$, tidal volume $(>5 \mathrm{~mL} \times$ body weight $[\mathrm{kg}])$, No tracheal secretions, $\mathrm{PaO}_{2} / \mathrm{F}_{\mathrm{I}} \mathrm{O}_{2}>300 \mathrm{mmHg}$; (3) stable circulatory dynamics; (4) recovery of muscle strength: hold head for $5 \mathrm{~s}$ or more, hold/open hand, TOF ratio 0.9 or more; (5) no abnormalities on chest X-ray before extubation. Because many anesthesiologists regard extubation times over $15 \mathrm{~min}$ as indicative of poor recovery [9], the time from the discontinuation of sedative agents to extubation was regarded as the primary endpoint of the present study.

We performed logistic regression analysis to assess the association of various factors with delayed extubation. In both age groups, delayed extubation was associated with the male sex $(<65$ years: $P<0.001 ; \geq 65$ years: $P<0.001)$, brain surgery $(<65$ years: $P=0.004 ; \geq 65$ years: $P<0.001)$, and selection of sedative agents $(<65$ years: $P<0.001$; $\geq 65$ years: $P=0.006$ ). In the $<65$ years group, delayed extubation was also associated with emergency surgery $(P=0.048)$. In the $\geq 65$ years group, delayed extubation was associated with age $(P<0.001)$, cervical surgery $(P<0.001)$, abdominal surgery $(P=0.032)$, and orthopedic surgery $(P=0.028)$. Other comorbidities, intraoperative fluid balance, bleeding, and operation time were not associated with delayed extubation (Fig. 1). As a result, the influence of the anesthesiologist's decision on delayed extubation was greater in the elderly. In addition, our findings suggest that extubation in patients who were 65 years or older was more delayed during cervical surgery.

\footnotetext{
* Correspondence: dynamis_air@yahoo.co.jp

Department of Anesthesiology and Perioperative Medicine, Tohoku

University Graduate School of Medicine, 2-1 Seiryomachi, Aoba, Sendai, Miyagi 980-8575, Japan
} 


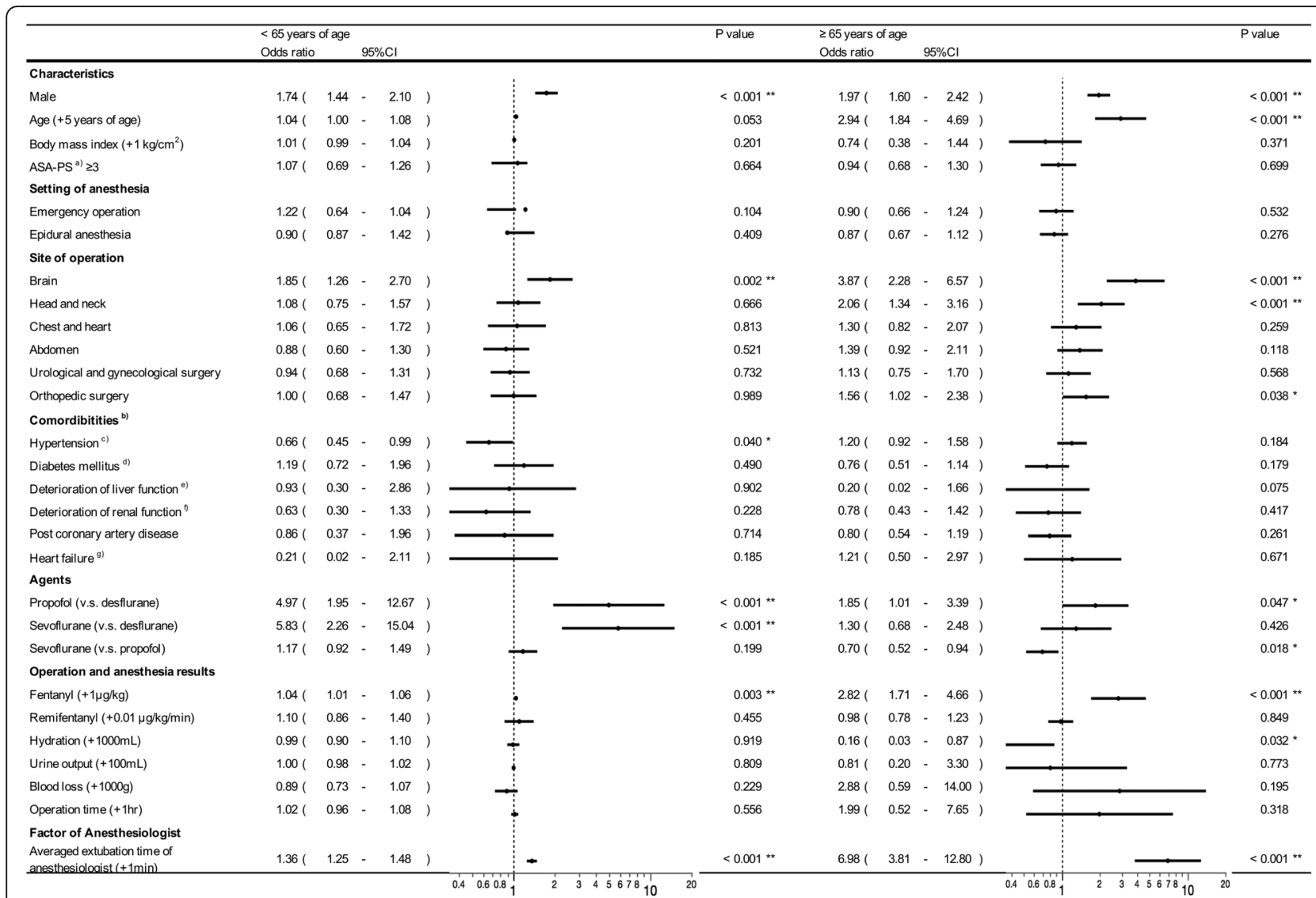

Fig. 1 Association between various clinical factors and delayed extubation (> $15 \mathrm{~min}$ ). Statistical analysis was performed using a multiple logistic regression model. For quantitative data, odds ratios are described per value in parentheses. ${ }^{*} P<0.05,{ }^{* *} P<0.01$. ${ }^{a}$ American Society of Anesthesiologists physical status. ${ }^{b}$ Comorbidities were extracted from the anesthesia ledger system (JSA-PIMS from Japanese Society of Anesthesiologists). 'Hypertension was defined as systolic blood pressure $\geq 140 \mathrm{mmHg}$, diastolic blood pressure as $\geq 90 \mathrm{mmHg}$, or the use of medications for blood pressure control. ${ }^{\mathrm{d} D i a b e t e s}$ mellitus was defined as the use of oral hypoglycemic agents or insulin. ${ }^{e}$ Deterioration of liver function was defined as AST $>32$, ALT $>37$, or the presence of cirrhosis. fDeterioration of renal function was defined as estimated GFR $<60 \mathrm{~mL} /$ min/1.73m². ${ }^{9}$ Heart failure was defined based on Framingham criteria [10].

In conclusion, our findings indicate that the influence of the anesthesiologist's decision on delayed extubation was greater in patients $\geq 65$ years of age. In addition, our findings suggest that extubation during cervical surgery was more delayed in patients who were 65 years or older.

\section{Acknowledgements}

Editorial support in the form of medical rewriting was provided by Editage.

\section{Authors' contributions}

NK helped with the data collection and analysis, manuscript preparation, and revision. TW, TS, HT, and YE helped with the manuscript revision. MY helped with conception, data analysis, manuscript revision, and final approval. The authors read and approved the final manuscript.

\section{Funding}

This work was supported by JSPS KAKENHI Grant Number 19 K18343.

Availability of data and materials

Not applicable.
Ethics approval and consent to participate

Ethical approval was obtained from the Ethics Committee of Tohoku University Graduate School of Medicine (reference number: 2015-1-533). The requirement for informed consent was waived due to the retrospective nature of the study.

\section{Consent for publication}

Not applicable.

\section{Competing interests}

The authors declare that they have no competing interests.

Received: 24 December 2019 Accepted: 25 February 2020 Published online: 13 March 2020

\section{References}

1. Eger El 2nd, Eisenkraft JB, Weiskopf RB. Miller's Anesthesia. 7th ed. Philadelphia: Churchill Livingstone Elsevier; 2009. p. 539-59.

2. Eger El 2nd, Eisenkraft JB, Weiskopf RB. The pharmacology of inhaled anesthetics: the distinguished professor program; 2007. p. 6-19.

3. Wu ZF, Jian GS, Lee MS, Lin C, Chen YF, Chen YW, et al. An analysis of anesthesia-controlled operating room time after propofol-based total intravenous anesthesia compared with desflurane anesthesia in ophthalmic surgery: a retrospective study. Anesth Analg. 2014;119(6):1393-406. 
4. Dexter F, Bayman EO, Epstein RH. Statistical modeling of average and variability of time to extubation for meta-analysis comparing desflurane to sevoflurane. Anesth Analg. 2010;110(2):570-80.

5. Wachtel RE, Dexter F, Epstein RH, Ledolter J. Meta-analysis of desflurane and propofol average times and variability in times to extubation and following commands. Can J Anaesth. 2011;58(8):714-24.

6. Vitez TS, Macario A. Setting performance standards for an anesthesia department. J Clin Anesth. 1998;10(2):166-75.

7. Apfelbaum JL, Grasela TH, Hug CC Jr, McLeskey CH, Nahrwold ML, Roizen MF, et al. The initial clinical experience of 1819 physicians in maintaining anesthesia with propofol: characteristics associated with prolonged time to awakening. Anesth Analg. 1993;77(4 Suppl):S10-4.

8. Masakazu N. Awakening from anesthesia. In: Japan Society of Anesthesiologists perioperative management team project, editors. Perioperative management team text: perioperative care. 2nd edition ed. Tokyo: Japan Society of Anesthesiologists; 2011. p.369-76

9. White PF, Tang J, Wender RH, Yumul R, Stokes OJ, Sloninsky A, et al. Desflurane versus sevoflurane for maintenance of outpatient anesthesia: the effect on early versus late recovery and perioperative coughing. Anesth Analg. 2009;109:387-93.

10. McKee PA, Castelli WP, MCNamara PM, Kannel WB. The natural history of congestive heart failure: the Framingham study. N Engl J Med. 1971;285 $1441-6$

\section{Publisher's Note}

Springer Nature remains neutral with regard to jurisdictional claims in published maps and institutional affiliations.

\section{Submit your manuscript to a SpringerOpen ${ }^{\circ}$ journal and benefit from:}

- Convenient online submission

- Rigorous peer review

- Open access: articles freely available online

- High visibility within the field

- Retaining the copyright to your article

Submit your next manuscript at $\boldsymbol{\nabla}$ springeropen.com 